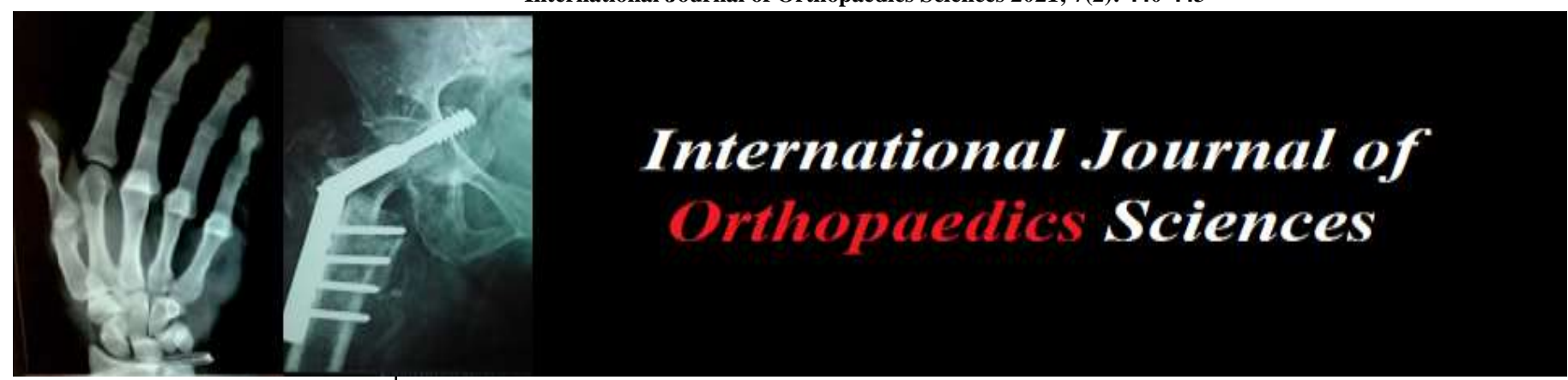

E-ISSN: 2395-1958

P-ISSN: 2706-6630

IJOS 2021; 7(2): 440-443

(C) 2021 IJOS

www.orthopaper.com

Received: 15-02-2021

Accepted: 22-03-2021

Dr. Santosh Veershetty Patil Assistant Professor, Department of Orthopaedics, Maheshwara Medical College and Hospital, Isnapur, Telangana, India

\section{Management of intertrochanteric hip fractures by proximal femoral nail and dynamic hip screw fixation: A comparative study}

\section{Dr. Santosh Veershetty Patil}

DOI: https://doi.org/10.22271/ortho.2021.v7.i2f.2661

\begin{abstract}
Intertrochanteric fractures are significantly increasing in older adults. Treatment choices for trochanteric fractures include intramedullary nail and extra medullary fixation, even though the appropriate treatment choices for such fractures remain controversial. The present study was aimed to assess optimal treatment option for intertrochanteric fractures to determine which method i.e. proximal femoral nailing (PFN) and dynamic hip screw fixation (DHS) gives minimal post-operative complications, minimal blood loss and minimal duration surgery. A total of 46 cases with intertrochanteric fractures attending Department of Orthopedics were recruited. Cases were randomly allocated to PFN (Group 1) and DHS (Group 2). The intra-operative, early and late complications were recorded, and the functional outcome of each group was assessed. Road traffic accidents were most common cause of fractures in both groups. In group 1, the mean length of incision $(9.56 \mathrm{~cm})$, duration of surgery $(71.45 \mathrm{~min})$, fluoroscopy time $(72.66)$ and total intraoperative blood loss $(138 \mathrm{ml})$. In group 2, the mean length of incision $(15.89 \mathrm{~cm})$, duration of surgery $(89.18 \mathrm{~min})$, fluoroscopy time $(59.38)$ and total intraoperative blood loss $(322 \mathrm{ml})$. Cases treated with PFN had excellent outcome in $21.7 \%$, good in $69.56 \%$, fair in $8.69 \%$ and none of the case had poor outcome. Whereas in DHS group, excellent outcome in $21.7 \%$, good in $43.47 \%$, fair in $21.7 \%$ and poor in $13.04 \%$. Both PFN and DHS had similar functional outcome. However, PFN had significantly more desirable functional outcome. PFN requires a smaller incision, shorter surgical duration, less intraoperative blood loss and post-operative complication than DHS group.
\end{abstract}

Keywords: Intertrochanteric fractures, proximal femoral nailing (PFN), dynamic hip screw (DHS), Functional outcome

\section{Introduction}

The intertrochanteric fracture incidence has been significantly increasing in older adult population due to trivial trauma and osteoporosis and in younger population due to high velocity trauma ${ }^{[1]}$. The surgical management was primary treatment choice for intertrochanteric fractures. It is always aims to restore the anatomy and function without prolonged immobilization ${ }^{[2]}$.

Surgical management with stable fixation allows early mobilization and reduces postoperative complications. Intramedullary fixation and extra medullary fixation are major treatment options for the intertrochanteric fractures ${ }^{[3]}$. The dynamic hip screw fixation (DHS) method is a standard implant method and commonly employed in extra medullary fixation ${ }^{[4]}$. Proximal femoral nail (PFN) is commonly used treatment method in intramedullary fixation. In recent years, PFN is extensively used in the treatment of intertrochanteric fractures because it was improved by addition of an antirotation hip screw proximal to the main screw. However, literature suggested that there are benefits and technical failures of PFN in the management of trochanteric fractures ${ }^{[5,6]}$. There is a controversial statement regarding the efficacy of PFN and DHS in the operative management of intertrochanteric fractures. The present study was aimed to assess optimal treatment option for intertrochanteric fractures to determine which method i.e. PFN and DHS gives minimal post-operative complications, minimal blood loss and minimal duration surgery.
Corresponding Author: Dr. Santosh Veershetty Patil Assistant Professor, Department of Orthopaedics, Maheshwara Medical College and Hospital, Isnapur, Telangana, India 


\section{Material and Methods}

The present prospective interventional study was conducted in the Department of Orthopedics, Maheshwara Medical College and Hospital, Isnapur, Telangana from June 2018 to March 2021. A total of 46 cases with intertrochanteric fractures attending Department of Orthopedics were recruited. Cases with intertrochanteric fracture, above 21 years of age, cases who were fit for anaesthesia and willing to participate in the study were included. Cases with fractures associate with polytrauma, pathological fractures, active infection, deformity of femur, non-traumatic disorder, abnormal bowing of femur, osteopetrosis and cases not willing to participate in the study were excluded. Informed consent was obtained from all the study participants and the study protocol was approved by the institutional ethics committee.

Study cases were randomly allocated to two groups (23 in each group) and surgically managed with proximal femoral nailing (Group 1) and dynamic hip screw fixation (Group 2). The fractures were classified according to JensenMichaelsen's modification of Evans classification of trochanteric fractures. Type I \& II fractures were considered as stable fractures, type III, IV \& V fractures considered as unstable fractures. The study participants were evaluated as per the clinical history and mode of injury. Necessary radiological investigations such as X-ray (antero-posterior and lateral view) and complete haemogram was performed.
Closed reduction was attempted in all cases to reduce fractures. Post operatively all the cases underwent rehabilitation protocol with dynamic quadriceps and ankle pump exercises being started with walker from the second and third day. Depending on the patient condition, stability of fracture and adequacy of fixation non-weight bearing and later partial weight bearing was started. All the cases were advised to follow up at the end of $6^{\text {th }}$ week after discharge, 3 months and 6 months. Clinical and radiological evaluation by $\mathrm{X}$-rays was done to assess the status of fracture union and signs of failure of fixation. Walking ability of each patient was recorded and compared with pre-injury walking ability using the Sahlstrand74 grading. Postoperative pain was evaluated using the four-point pain score as also used by Saudan (Excellent, good, fair and poor). The fracture union was considered as malunion if varus angulation was greater than 10 degrees.

The SPSS version 23 software was used to carry out statistical analysis relevant to the study. Descriptive statistics were used to represent demographic and clinical characteristics in the form of frequency and percentages. Student t- test, chi square test was used to compare the outcomes between two study groups. $P<0.05$ was considered as statistically significant.

\section{Results}

Table 1: Demographic details of study participants $(n=46)$.

\begin{tabular}{|c|c|c|c|c|c|}
\hline \multirow{2}{*}{ Demographic parameters } & \multicolumn{2}{|c|}{ Group $1($ PFN $)(n=23)$} & \multicolumn{2}{|c|}{ Group 2 (DHS) $(n=23)$} & \multirow{2}{*}{ p-value } \\
\hline & Frequency & Percentage & Frequency & Percentage & \\
\hline \multicolumn{6}{|c|}{ Age (In years) } \\
\hline $21-30$ & 02 & $8.69 \%$ & 02 & $8.69 \%$ & \multirow{6}{*}{0.282} \\
\hline $31-40$ & 03 & $13.04 \%$ & 02 & $8.69 \%$ & \\
\hline $41-50$ & 04 & $17.3 \%$ & 05 & $21.7 \%$ & \\
\hline $51-60$ & 06 & $26.08 \%$ & 05 & $21.7 \%$ & \\
\hline $61-70$ & 06 & $26.08 \%$ & 08 & $34.7 \%$ & \\
\hline Above 70 & 02 & $8.69 \%$ & 01 & $4.34 \%$ & \\
\hline \multicolumn{6}{|c|}{ Gender } \\
\hline Male & 09 & $39.13 \%$ & 11 & $47.8 \%$ & \multirow{2}{*}{0.314} \\
\hline Female & 14 & $60.86 \%$ & 12 & $52.1 \%$ & \\
\hline \multicolumn{6}{|c|}{ Laterality of fracture } \\
\hline Unilateral right & 10 & $43.47 \%$ & 12 & $52.1 \%$ & \multirow{3}{*}{0.261} \\
\hline Unilateral left & 13 & $56.5 \%$ & 11 & $47.8 \%$ & \\
\hline Bilateral & - & - & - & - & \\
\hline \multicolumn{6}{|c|}{ Mode of injury } \\
\hline RTA & 13 & $56.5 \%$ & 15 & $65.21 \%$ & \multirow{4}{*}{0.588} \\
\hline Fall from height & 06 & $26.08 \%$ & 05 & $21.73 \%$ & \\
\hline Slipping and fall & 03 & $13.04 \%$ & 03 & $13.04 \%$ & \\
\hline Assault & 01 & $4.34 \%$ & - & - & \\
\hline \multicolumn{6}{|c|}{ Jensen-Michaelsen's modification of Evans classification of fracture type } \\
\hline Type 1 fractures & 01 & $4.34 \%$ & 02 & $8.69 \%$ & \multirow{6}{*}{0.438} \\
\hline Type 2 fractures & 15 & $65.21 \%$ & 10 & $43.47 \%$ & \\
\hline Type 3 fractures & 03 & $13.04 \%$ & 08 & $34.7 \%$ & \\
\hline Type 4 fractures & 04 & $17.13 \%$ & 03 & $13.04 \%$ & \\
\hline Type 5 fractures & - & - & - & - & \\
\hline Type 6 fractures & - & - & - & - & \\
\hline
\end{tabular}

Table 2: Intra-operative variables in the study participants

\begin{tabular}{|c|c|c|c|}
\hline \multirow{2}{*}{ variables } & Group 1 & Group 2 & \multirow{2}{*}{ p-value } \\
\cline { 2 - 3 } & Mean \pm SD & Mean \pm SD & \\
\hline Length of incision & $9.56 \pm 1.24$ & $15.89 \pm 2.03$ & 0.0029 \\
\hline Duration of Surgery & $71.45 \pm 2.61$ & $89.18 \pm 5.63$ & 0.0031 \\
\hline Fluoroscopy time & $72.66 \pm 6.65$ & $59.38 \pm 2.80$ & 0.0022 \\
\hline Amount of blood loss & $138 \pm 18.96$ & $322 \pm 33.21$ & 0.002 \\
\hline
\end{tabular}




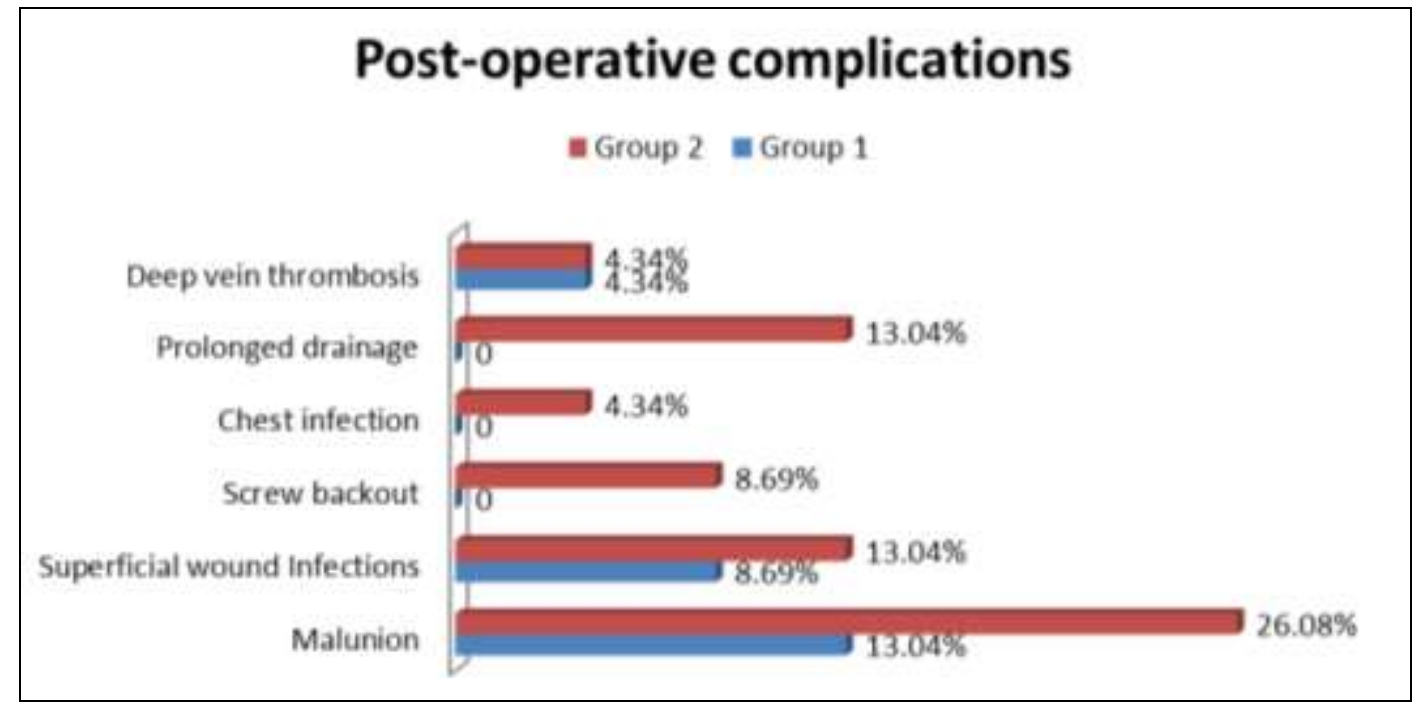

Fig 1: Postoperative complication in the study participants

Table 3: Post-operative variables in the study participants

\begin{tabular}{|c|c|c|c|}
\hline \multirow{2}{*}{ Post-operative Variables } & Group 1 & Group 2 & \multirow{2}{*}{ p-value } \\
\cline { 2 - 3 } & Mean \pm SD & Mean \pm SD & \\
\hline \multicolumn{2}{|c|}{ Post-operative pain score } & \\
\hline Score 1 & $10(43.47 \%)$ & $05(21.73 \%)$ & \\
\hline Score 2 & $12(52.17 \%)$ & $08(34.7 \%)$ & \multirow{2}{*}{0.031} \\
\hline Score 3 & $01(4.34 \%)$ & $08(34.7 \%)$ & \\
\hline Score 4 & - & $02(8.69 \%)$ & \\
\hline Mobility score & $1.64 \pm 0.40$ & $2.31 \pm 0.57$ & 0.026 \\
\hline Shortening & $0.69 \pm 0.98$ & $1.37 \pm 0.86$ & 0.002 \\
\hline Range of movement & $99.12 \pm 5.62$ & $86.74 \pm 8.36$ & 0.061 \\
\hline Time of fracture union & $13.2 \pm 2.30$ & $12.8 \pm 1.66$ & 0.628 \\
\hline
\end{tabular}

Table 4: Overall functional outcome in both the study groups

\begin{tabular}{|c|c|c|c|c|}
\hline \multirow{2}{*}{$\begin{array}{c}\text { Functional } \\
\text { outcome }\end{array}$} & \multicolumn{2}{|c|}{ Group 1 } & \multicolumn{2}{c|}{ Group 2 } \\
\cline { 2 - 5 } & Frequency & Percentage & Frequency & Percentage \\
\hline Excellent & 05 & $21.7 \%$ & 05 & $21.7 \%$ \\
\hline Good & 16 & $69.56 \%$ & 10 & $43.47 \%$ \\
\hline Fair & 02 & $8.69 \%$ & 05 & $21.7 \%$ \\
\hline Poor & - & - & 03 & $13.04 \%$ \\
\hline p-value & \multicolumn{4}{|c|}{0.0276} \\
\hline
\end{tabular}

\section{Discussion}

A total of 46 cases with intertrochanteric fractures attending Department of Orthopedics were recruited. Study cases were randomly allocated to two groups (23 in each group) and surgically managed with proximal femoral nailing (Group 1) and dynamic hip screw fixation (Group 2). In group 1, majority cases were between $51-70$ years $(52.16 \%)$, followed by $41-50$ years $(17.3 \%), 31-40$ years $(13.04 \%), 21-30$ years $(8.69 \%)$ and above 70 years $(8.69 \%)$. In group 2 , majority cases were belonged age group 51-70 years (56.4\%), followed by $41-50$ years $(21.7 \%), 21-30(8.69 \%), 31-40(8.69 \%)$ and above 70 years $(4.34 \%)$. The difference between two study groups was statistically not significant $(\mathrm{p}=0.282)$. Female participants were more than males in both the study groups (Table 1). A study by Tanay R. Prabhoo included 40 cases with mean age of 56.6 years and 58.5 years treated with PFN and DHS respectively ${ }^{[7]}$.

In group 1, fractures were seen right side in $43.47 \%$ cases and left side in $56.5 \%$ cases. In group 2, fractures were seen right limb in $52.1 \%$ cases and left side in $47.8 \%$ cases. A study by Tanay R. Prabhoo noticed in PFN group, 12(60\%) patients were found to have proximal femoral fractures on the left side while $8(4 \%)$ patients were having fracture on the right side.
Amongst the 20 cases operated by DHS, 9(45\%) patients were found to have proximal femoral fractures on the left side while $11(55 \%)$ patients were having fracture on the right side [7]. In both groups, road traffic accidents were leading cause of injury (56.5\% in group $1 \& 65.21 \%$ in group 2$)$, followed by falling from height injuries $(26.08 \%$ in group $1 \& 21.73 \%$ in group 2), falling by slipping (13.04\% in both groups) and assault (4.34\% in group 1). The difference was statistically not significant $(\mathrm{p}=0.588)$ (Table 1). Domestic fall was commonest cause of injury followed by road traffic accident and assault in both the study groups ${ }^{[7]}$.

The mean difference between intra-operative variables was statistically significant between two study groups. In group 1, the mean length of incision was $9.56 \mathrm{~cm}$, duration of surgery was $71.45 \mathrm{~min}$, fluoroscopy time was 72.66 and total intraoperative blood loss was $138 \mathrm{ml}$. In group 2, the mean length of incision was $15.89 \mathrm{~cm}$, duration of surgery was $89.18 \mathrm{~min}$, fluoroscopy time was 59.38 and total intraoperative blood loss was $322 \mathrm{ml}$ (Table 2). A study by Tanay R. Prabhoo observed high blood loss in DHS group but the radiation exposure was less as compared to the PFN group. Duration of surgery, hospital stay and implant failure was found to be more among patients in DHS group ${ }^{[7]}$. The Comparison of early and late intra operative complication rates was not statistically significant between study groups ${ }^{[8]}$. A study by Anmol Sharma et al. noted that the mean length of incision $(P<0.01)$, duration of surgery $(P<0.01)$ was less in PFN group and radiation exposures were significantly more in PFN group. Average blood loss was more in DHS group $(P<0.01)^{[3]}$. In this study the mean length of incision was less in PFN group than DHS group, which was comparable with the studies by Pan et al. and Zhao et al. ${ }^{[12,13]}$

The post-operative complication was observed in group 1 such as malunion (13.04\%), superficial wound infection $(8.69 \%)$ and deep vein thrombosis $(4.34 \%)$. In group 2, malunion $(26.08 \%)$ was commonest complication, followed by superficial wound infection $(13.04 \%)$, prolonged drainage (13.04\%) and deep vein thrombosis (4.34\%) (Figure 1). A study by Venkatesh Gupta SK, Veera Shekar Valisetti noted prolonged drainage, hematoma, superficial infection and deep vein thrombosis ${ }^{[8]}$. In group 1 , the postoperative pain score was 1 in $43.47 \%$ of cases, 2 in $52.17 \%$ and 3 in $4.34 \%$ cases. In group 2, the postoperative pain score was 1 in $21.73 \%$ of cases, 2 in $34.7 \%, 3$ in $34.7 \%$ cases and 4 in $8.69 \%$ cases. The difference of pain score between two study groups was 
statistically significant $(\mathrm{p}=0.031)$. In group 1 , the mean postoperative mobility score was 1.64 , post-operative shortening was 0.69 , post-operative range of movement was 99.12 and time period of fracture reunion was 13.2. In group 2, the mean post-operative mobility score was 2.31 , post-operative shortening was 1.37 , post-operative range of movement was 86.74 and time period of fracture reunion was 12.8 . The mean difference of post-operative study variables between two study groups was statistically significant $(P<0.05)$ (Table 3$)$. The overall functional outcome in group 1 treated with proximal femoral nailing was excellent in $21.7 \%$ cases, good in $69.56 \%$ cases, fair in $8.69 \%$ cases and none of the case had poor outcome. The overall functional outcome in in group 2 treated with dynamic hip screw fixation was excellent in $21.7 \%$ cases, good in $43.47 \%$ cases, fair in $21.7 \%$ cases and poor in $13.04 \%$ cases (Table 4 ). A study by Tanay R. Prabhoo found excellent functional outcome in 5 cases, good in 10 cases, fair in 4 cases and poor in 1 case in DHS group. Whereas in PFN group 7 cases had excellent results 12 cases had good results, 1 case had fair results and none had poor results (7). A study by Venkatesh Gupta SK, Veera Shekar Valisetti observed $37.5 \%$ excellent results, good results in $54.1 \%$, fair results in $6.6 \%$, and poor results in $1.6 \%$ cases in DHS group and $66.2 \%$ excellent results, good results in $28.2 \%$, fair in $5 \%$ and none had poor function outcome in PFN group (8). The results of above studies are compatible with the functional outcome of the present study.

A study by Tanay R. Prabhoo concluded that PFN emerged to be superior to DHS in unstable intertrochanteric fractures ${ }^{[7]}$. A study by Venkatesh Gupta SK, Veera Shekar Valisetti concluded that DHS and PFN have matched outcomes in stable trochanteric fractures and PFN has greater functional outcome with unstable fractures ${ }^{[8]}$. A study by Anmol Sharma et al. concluded that PFN provides a shorter surgery with smaller incision. However, the incidence of technical errors was significantly higher in PFN than DHS ${ }^{[9]}$. A metaanalysis by Xiao Huang et al concluded that PFN fixation shows the same effectiveness as DHS fixation ${ }^{[10]}$. A clinical trial by Adams CI et al. concluded that the use of an intramedullary device in the management of intertrochanteric femoral fractures is still associated with a higher but nonsignificant risk of postoperative complications and is not recommended in place of standard treatment modality like dynamic hip screw and plate ${ }^{[11]}$. A study by Xianshang Zeng et al. concluded that PFN had better functional outcomes than DHS among elderly cases with osteoporosis ${ }^{[14]}$. A study by Herode $\mathrm{P}$ et al. concluded that both fixative methods are accurate, tested \& needs good surgical skill. There is no much difference in complications in these two techniques ${ }^{[15]}$.

\section{Conclusion}

The results of the present study conclude that in the management of stable intertrochanteric fractures, both proximal femoral nailing and dynamic hip screw had similar functional outcome. However in the management of unstable fractures PFN had significantly more desirable functional outcome. PFN requires a smaller incision, shorter surgical duration and had less intraoperative blood loss. Post-operative complication was less in PFN group than DHS group. Hence, proximal femoral nailing is a better fixation tool for intertrochanteric fracture of femur than dynamic hip screw.

\section{References}

1. Kannus P, Parkkari J, Sievänen $\mathrm{H}$ et al: Epidemiology of hip fractures. Bone, 1996;18(1):57-63.
2. Yadav S, Srivastava DC, Shukla M. Comparative evaluation of dynamic hip screw and proximal femoral nail for fracture of intertrochanteric femur. Int $\mathbf{J}$ Res Orthop 2016;2:286-90.

3. Kairui Zhang, Sheng Zhang, Jun Yang et al. Proximal Femoral Nail vs. Dynamic Hip Screw in Treatment of Intertrochanteric Fractures: A Meta-Analysis. Med Sci Monit 2014;20:1628-1633.

4. Saarenpää I, Heikkinen T, Ristiniemi J et al: Functional comparison of the dynamic hip screw and the Gamma locking nail in trochanteric hip fractures: a matched-pair study of 268 patients. Int Orthop 2009;33(1):255-60.

5. Nuber S, Schönweiss T, Rüter A. Stabilisation of unstable trochanteric femoral fractures. Dynamic hip screw (DHS) with trochanteric stabilisation plate $v s$. proximal femur nail (PFN). Unfallchirurg 2003;106(1):39-47.

6. Pires RE, Santana EO Jr, Santos LE et al. Failure of fixation of trochanteric femur fractures: clinical recommendations for avoiding Z-efect and reverse Zefect type complications. Patient Saf Surg 2011;22:17.

7. Tanay R Prabhoo. Comparative study between dynamic hip screw and proximal femoral nail in the management of trochanteric and sub trochanteric fractures. International Journal of Contemporary Medical Research 2018;5(10):J12-J17.

8. Venkatesh Gupta SK, Veera Shekar Valisetti. Comparative study between dynamic hip screw vs proximal femoral nailing in inter-trochanteric fractures of the femur in adults. International Journal of Orthopaedics Sciences 2015;1(1):07-11.

9. Anmol Sharma, Anisha Sethi, Shardaindu Sharma. Treatment of stable intertrochanteric fractures of the femur with proximal femoral nail versus dynamic hip screw: a comparative study. Rev Bras Orthop 2018;53(4):477-481.

10. Xiao Huang, Frankie Leung, Zhou Xiang, Pei-Yong Tan, Jing Yang, Dai-Qing Wei et al. Proximal Femoral Nail versus Dynamic Hip Screw Fixation for Trochanteric Fractures: A Meta-Analysis of Randomized Controlled Trials. The Scientific World Journal 2013,1-8. http://dx.doi.org/ 10.1155/2013/805805.

11. Adams CI, Robinson CM, Court-Brown CM, McQueen MM. Prospective randomized controlled trial of an intramedullary nail versus dynamic screw and plate for intertrochanteric fractures of the femur. J Orthop Trauma. 2001;15(6):394-400.

12. Pan XH, Xiao DM, Lin BW. Dynamic hip screws (DHS) andproximal femoral nails (PFN) in treatment of intertrochantericfractures of femur in elderly patients. Chin J Orthop Trauma 2004;7:785-9.9.

13. Zhao C, Liu DY, Guo JJ, Li LP, Zheng YF, Yang HB, et al.Comparison of proximal femoral nail and dynamic hip screwfor treating intertrochanteric fractures. Zhongguo Gu Shang 2009;22(7):535-7.

14. Xianshang Zeng, Nan Zhang, Dan Zeng et al. Proximal femoral nail antirotation versus dynamic hip screw fixation for treatment of osteoporotic type 31-A1 intertrochanteric femoral fractures in elderly patients. Journal of International Medical Research 2017;45(3)1109-1123.

15. Herode P, Shroff A, Sadaria M, Jeegar P. Comparison of PFN (Proximal femoral nail) and DHS (Dynamic hip screw) in treatment of Intertrochanteric femur fractures. Surgical Update: Int J surg Orthopedics 2018;4(1):37-44. 